\title{
VALIDATION OF CONTINUOUS NEONATAL VENTILATOR RESPIRATORY MECHANICS AND TIDAL VOLUME BY SELECTED OPTIMAL RESPIRATORY CYCLES
}

\author{
V. Rigo ${ }^{1}$, E. Graas ${ }^{2}$, J. Rigo $^{1}$ \\ ${ }^{I}$ Neonatology, University of Liège, CHU de Liège (CHR), ${ }^{2}$ Nomics, Liège, Belgium
}

\begin{abstract}
Aim: To assess on-line ventilator respiratory mechanics $(\mathrm{RM})$ parameters, including tidal volume $\left(\mathrm{V}_{\mathrm{T}}\right)$.
\end{abstract}
Methods: Ten recordings of ventilated newborns (10 minutes, synchronized intermittent mandatory ventilation (SIMV) and assist/control (AC)) were analyzed. Ventilator provided RM data (VRC, ventilator respiratory cycles) every ten seconds. Continuous pressure $(\mathrm{P})$ and flow $\left(\mathrm{V}^{\prime}\right)$ recordings were used to reconstruct $\mathrm{P}, \mathrm{V}^{\prime}$ and volume $(\mathrm{V})$ waves, and $\mathrm{PV}, \mathrm{PV}^{\prime}$ and $\mathrm{V}^{\prime} \mathrm{V}$ loops. Visual assessment determined assisted leak-free optimal respiratory cycles (SRC, selected respiratory cycles) used to calculate RM values. We compared mean values and their variability according to ventilatory mode and type of cycles.

Results: In AC, $\mathrm{V}_{\mathrm{T}}$ decrease from $5.6 \pm 1.8 \mathrm{~mL} / \mathrm{kg}$ (VRC) to $4.8 \pm 1.0 \mathrm{~mL} / \mathrm{kg}$ (SRC). In SIMV, $\mathrm{V}_{\mathrm{T}}$ tend to be lower for VRC $(4.4 \pm 1.1 \mathrm{~mL} / \mathrm{kg})$ than for SRC $(5.6 \pm 1.2 \mathrm{~mL} / \mathrm{kg})$. Also, assisted breaths $\mathrm{V}_{\mathrm{T}}$ differ according to ventilatory mode. Averaged RM mean values are similar apart for $\mathrm{C} 20 / \mathrm{C}$, that drops from 1.8 (VRC) to 1.2 (SRC). Ventilator C20/C are often out of classical range. Coefficients of variation for dynamic resistance, compliance, $\mathrm{V}_{\mathrm{T}}$ and $\mathrm{C} 20 / \mathrm{C}$ improve from 36, 35, 40, and 33\% for VRC to 27, 26, 18 and 24\% for SRC respectively.

Conclusion: Ventilator reports $\mathrm{V}_{\mathrm{T}} 16 \%$ above those effectively provided in $\mathrm{AC}$ assisted breaths, decreasing $\mathrm{V}_{\mathrm{T}}$ validity to assess ventilator settings adequacy. SIMV VT values don't reflect inspiratory pressure influence either. Careful selection of respiratory cycles to calculate RM values improves accuracy and decreases their high variability to clinically acceptable levels. 